\title{
Value of laparoscopy in the diagnosis and management of pancreatic carcinoma
}

\author{
A. CUSCHIERI, A. W. HALL, AND JOHN CLARK \\ From the Department of Surgery, University of Dundee, Dundee,
}

SUMMARY Our experience with laparoscopy in the diagnosis and staging of 23 cases of pancreatic cancer is reported. This endoscopic procedure has proved useful in the diagnosis of the disease, in the assessment of operability, and in the retrieval of material for histological and cytological confirmation of pancreatic cancer. An infra-gastric laparoscopic method for inspection of the body and tail of the pancreas is described and the technique may allow the earlier detection of neoplasms in this region.

The incidence of carcinoma of the pancreas is rising on both sides of the North Atlantic. Approximately 22000 new cases are seen a year in the United States (American Cancer Society, 1975), and 4400 per year in the United Kingdom (Registrar General, 1975). Of these, over $90 \%$ are dead within one year of detection. The late diagnosis of this disease is a major factor contributing to this poor prognosis. At the time of surgery the resectability rate is $60 \%$ for periampullary cancer, $20 \%$ for cancer of the head and 5 to $10 \%$ for cancer of the body and tail (Smith, 1961; Smith, 1973; Hermreck et al., 1974; Nakase et al., 1977). Resection remains the only hope of cure and appears to give reasonable palliation (Wilson and Block, 1974).

Techniques are required for the detection of early pancreatic cancer and to assess the stage of the disease at the time of presentation. In this paper we have reviewed our experience with laparoscopy both in the diagnosis and management of pancreatic cancer.

\section{Methods}

\section{TECHNIQUE}

The laparoscopies were performed using a Keymed 8 $\mathrm{mm}$ double puncture laparoscope with a tactile probe; insufflation of the abdomen with carbon dioxide was produced and maintained using a Semm's automatic pneumoinsufflator. This instrument has a flow indicator and a pressure gauge

Address for correspondence: Professor A. Cuschieri, Department of Surgery, Ninewells Hospital, Dundee DD1 9SY.

Received for publication 21 January 1978 which continuously monitors intra-abdominal pressure.

Laparoscopy was carried out, in all cases suspected of having pancreatic pathology, by a standard technique under general anaesthesia. A Verres needle was inserted through the linea alba immediately inferior to the umbilicus. The abdomen was inflated with carbon dioxide until it was firm to palpation, about 41 being required in most cases. The needle was removed. A $1 \mathrm{~cm}$ transverse incision was made through the linea alba, down to peritoneum, and the trocar/cannula inserted. An endviewing telescope was introduced through the cannula after reconnection of the insufflator. The peritoneal cavity was inspected for adhesions and any obvious hepatic pathology. The palpating probe was then inserted, via its cannula, under direct vision. The puncture for this was sited above the level of the umbilicus at the left lateral border of the rectus. The contents of the upper abdomen were then carefully inspected, particular attention being paid to the appearance of the liver, the presence of secondary deposits, and the state of distension of the gallbladder. The liver was raised to complete examination of the gallbladder. The presence of any masses in the area of the duodenal loop or in the retrogastric region was noted. Palpation, using the tactile probe, revealed the consistency of any swelling identified. Where a tumour of the pancreatic head or periampullary region was suspected, cholangiography was then performed. Contrast medium was introduced transhepatically into either the gallbladder or a dilated bile duct. In either case a $15 \mathrm{~cm}$ $23 \mathrm{G}(0.7 \mathrm{~mm}$ outside diameter) Chiba needle was used. When the bile duct route was chosen, the needle was passed through the skin in the right upper 
quadrant of the abdomen into the hepatic substance, towards the porta hepatis, under direct vision. Cholangiography was performed according to the technique of Okuda et al. (1974).

If a retrogastric mass had been detected, or preoperative investigation had suggested the possibility of a lesion of the body or tail of the pancreas, the lesser sac was then examined. The greater curvature of the stomach was lifted with the tip of the tactile probe and a transparent window in the omentum close to the greater curvature identified. This window was perforated with the tip of the probe and the telescope advanced through the aperture. A rapid inflow of carbon dioxide distended the lesser sac allowing inspection of the body and part of the tail of the gland (Fig. 1).

When examination of the pancreas was completed, any mass or other suspicious area in the pancreas was subjected to histological examination using an aspiration cytology technique. A $23 \mathrm{G}$ needle of the Chiba type was inserted into the lesion under direct vision. A $10 \mathrm{ml}$ syringe was attached to the needle and, while negative pressure was exerted, the needle was rapidly inserted and withdrawn through thelesion. The syringe wasremoved and $5 \mathrm{ml}$ of air drawn in. The contents of the needle were expressed onto one or more microscope slides and smears were immediately fixed in Carbowax. These were later stained by the Papanicolaou technique and examined by an experienced cytologist. On average, two such aspiration biopsies were taken from each lesion.

Any suspicious areas or nodules in the liver were submitted to biopsy by the Menghini technique, the cores being fixed in buffered formalin and sent for routine histopathology. Finally, the areas of needle puncture and biopsy were checked to ensure that haemostasis was adequate and bile leakage minimal, the abdomen was deflated and the laparoscope withdrawn.

\section{PATIENTS}

Over the four years 1973-77 23 patients with carcinoma of the pancreas or periampullary region were studied laparoscopically (Table 1). Fifteen presented with obstructive jaundice, but the gallbladder was palpable on clinical examination in only 10 .

The remainder included six patients with a hard epigastric mass, carcinoma of the pancreas being suspected preoperatively, and two patients with weight loss but without a definite preoperative diagnosis.

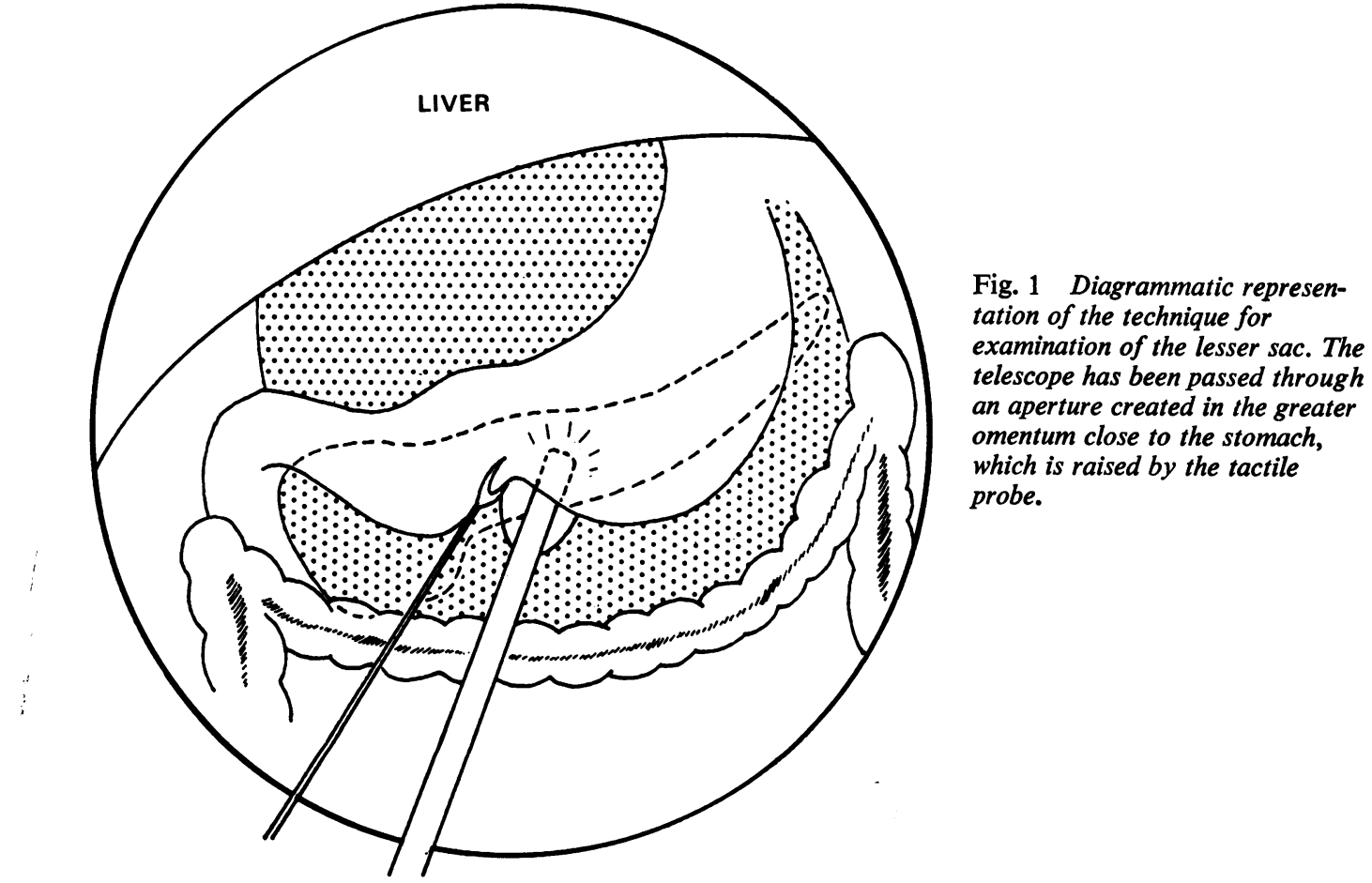


Table 1 Characteristics of patients undergoing laparoscopy for carcinoma of pancreas

\begin{tabular}{ll}
\hline Obstructive jaundice & 15 \\
Male: female ratio jaundiced patients & $13: 2$ \\
Ages (yr) & $42-73$ \\
Clinically palpable gallbladder & 10 \\
Clinically palpable liver & 15 \\
Eventual diagnosis & \\
$\quad$ Carcinoma head of pancreas & 6 \\
Periampullary carcinoma & 9 \\
Non-jaundiced patients & 8 \\
Male: female ratio & $4: 4$ \\
Palpable abdominal mass & 6 \\
Eventual diagnosis carcinoma of body and tail of pancreas & 8 \\
\hline
\end{tabular}

Over the same period, laparoscopic visualisation of the lesser sac was attempted in a further nine patients. To allow a more complete assessment of the technique the findings from these will also be discussed.

\section{Results}

\section{LESIONS OF PANCREATIC HEAD AND \\ PERIAMPULLARY REGION}

In all patients with obstructive jaundice (Table 2) the liver was seen, at laparoscopy, to be green and distended. Likewise the gallbladder was enlarged and resistant to indentation with the tactile probe. Secondary deposits were visible in the liver of three and, in two, deposits were also visible elsewhere in the peritoneal cavity. Laparoscopic cholangiography was undertaken in 13 and in every case confirmed the presence of an extrahepatic common bile duct obstruction within the head of the pancreas. In all cases the films were diagnostic, indicating the presence of a malignant stricture within the pancreatic head (Fig. 2).

Table 2 Laparoscopic findings in 15 patients with obstructive jaundice

Laparoscopic finding

Distended gallbladder

Green distended liver

Hepatic metastases

Metastatic deposits elsewhere in abdomen

Laparoscopic cholangiography performed

\begin{tabular}{l} 
No. \\
15 \\
15 \\
3 \\
2 \\
13 \\
\hline
\end{tabular}

Laparoscopy was followed by laparotomy in all 15 cases. The findings were confirmed on every occasion. In 10 of the patients resection proved possible, a pancreaticoduodenectomy with conservation of the body and tail of the pancreas being performed. Only one patient died before discharge from hospital. Non-resectional, palliative surgery was carried out in the other five (which included the three confirmed as having hepatic metastases). In four cases a choledochojejunostomy en-Y was performed and, in the

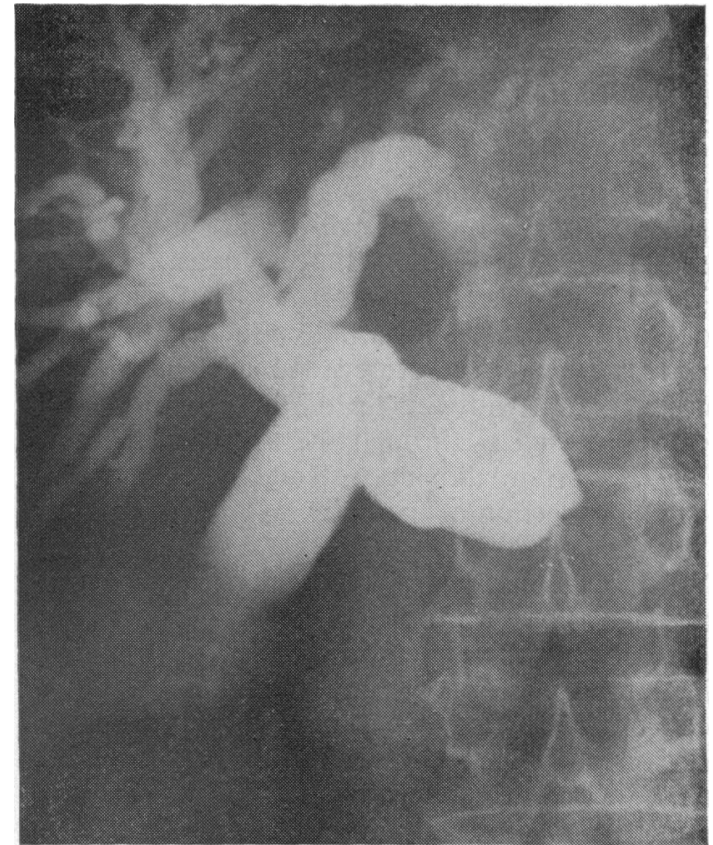

Fig. 2 A laparoscopic, transhepatic, fine needle cholangiogram showing a dilated biliary tree and a typical occlusion of the common bile duct in the pancreatic head due to pancreatic carcinoma.

fifth, adequate biliary drainage was obtained by the passage of a silastic stent through the tumour.

LESIONS OF PANCREATIC BODY AND TAIL The eight patients with pancreatic carcinoma who did not present with obstructive jaundice (Table 3) were found to have lesions of the body and tail. In all a large retrogastric mass was found which could easily be palpated with the tactile probe. Hepatic secondary deposits were seen in six cases and submitted to biopsy by the Menghini technique. Aspiration needle biopsy of the pancreatic lesion was performed in two cases and in each cytological confirmation of the diagnosis was obtained. Operative intervention was felt to be indicated in only one patient. Even here laparotomy merely confirmed the diagnosis, no procedure being feasible.

\section{VISUALISATION OF LESSER SAC}

In 10 laparoscopies visualisation of the lesser sac was attempted. The manoeuvre was successful in six. All of the four failures were in obese patients who had adhesions within the peritoneal cavity from previous surgery or inflammation. One patient was shown to have a retrogastric mass which on examination via the lesser sac could be seen to arise from the pancreas and was confirmed as being a carcinoma 
Table 3 Laparoscopic findings in eight patients not having obstructive jaundice

Laparoscopic finding

Large retrogastric mass

Mass hard on palpation using tactile probe

Aspiration needle biopsy performed

Hepatic metastases present

Hepatic metastases biopsied

No.

8

8

by needle biopsy of the lesion under direct vision. In three, laparoscopic examination of the body of the pancreas proved to be entirely normal. This was confirmed at laparotomy in two, one with a normal and the other with a positive isotope pancreatic scan. A normal pancreas was discovered in a fourth patient in whom laparoscopy had shown multiple intraperitoneal tumour deposits but where the site of the primary was unknown. Laparotomy confirmed pancreatic normality and failed to find the primary lesion. The remaining subject was shown to have a fibrous, featureless area at the expected site of the pancreas. A diagnosis of pancreatic atrophy was substantiated on opening the abdomen.

\section{Discussion}

Progress in the management of pancreatic neoplasia is hindered by the problem of arriving at a positive diagnosis while the lesion is still small. Many of the early symptoms are vague and common to other less sinister conditions. Diagnosis is best regarded as a two-stage process: the delineation of a high risk group and then positive confirmation. For the first step a simple screening test, which may be applied to anyone in whom the diagnosis is entertained, is needed. This must be non-invasive, simple, and should yield few, if any, false negative results. A serological test would be ideal and the initial results with pancreatic oncofetal antigen (POA) are encouraging (Gelder et al., 1978). Isotope pancreatic scanning and upper abdominal ultrasound are also candidates for this role. In a recent prospective study (Wood et al., 1976) isotope scanning gave the correct diagnosis in only $64 \%$ of cases. As the results of ultrasound examination were superior, this procedure may prove to be a useful investigation when pancreatic neoplasia is suspected on clinical or serological grounds.

With the advent of computerised tomography of the abdomen, radiology may yet provide a useful screening procedure. Initial experience with the method, as applied to the pancreas, has recently been reported from two major American institutions (Haaga et al., 1977; Sheedy et al., 1977). Changes in the size and shape of the gland are reliably detected but no difference in density between neoplastic and normal tissue has been seen. Wholly intrapancreatic lesions are thus missed unless dilatation of the biliary tree is present.

At the present time endoscopic retrograde cholangiopancreatography (ERCP) with or without aspiration or brush cytology (Endo et al., 1974; Osnes et al., 1975; Hatfield et al., 1976; Wood et al., 1976) remains the best method for confirming the diagnosis of pancreatic cancer. The true predictive value of this technique is high for lesions of the head and periampullary region but it often misses lesions of the body and tail. Although the number of patients in our series is small, the data suggest that laparoscopic techniques should be considered and developed further in the future.

The value of laparoscopy in hepatobiliary disorders is well documented (Sauer et al., 1973; Cuschieri, 1975). A survey of the literature reveals two reports from Germany on its use in studying the pancreas (Meyer-Burg et al., 1972; Kirstaedter and Meyer-Burg, 1973). In both cases the technique differed significantly from that described here, the pancreas being approached by the supragastric route. We have had no success with this approach. The infragastric route has proved satisfactory for examination of the lesser sac in the absence of fatladen omentum or peritoneal adhesions.

In this series, a thorough laparoscopic examination of the peritoneal cavity, combined with targeted cholangiography and aspiration biopsy, gave accurate diagnostic information about the pancreas in the majority of patients. Increasing expertise with laparoscopic examination of the body and tail of the pancreas by the infragastric route may lead to the detection of earlier, resectable lesions. The great advantage of this technique is that it permits needle biopsy of the pancreas under direct vision.

Christoffersen and Poll (1970) showed needle aspiration cytology of the pancreas to be a reliable technique when used at operation. Their experience has since been confirmed and amplified by others (Arnesjo et al., 1972; Shorey, 1975). Since then, the technique has been modified for use preoperatively using ultrasound (Smith et al., 1975; Hancke et al., 1975) or arteriography (Tylén et al., 1976) for guidance. The possibility that computerised tomography may allow accurate positioning of the needle, while avoiding major blood vessels, appears attractive. Within the foreseeable future it will not be practicable to screen the placement with computerised tomography and the radiation dose would, at present, be prohibitive. Direct vision permits more accurate placement of the needle within the tumour and reduces the risk of damage to other structures during its passage. So far, the reports on blind techniques are remarkably trouble-free, but on theoretical 
grounds risk of damage to bowel or major blood vessels does exist and, as yet, the reported series are very small. Peritoneoscopy allows examination of the lesion and placement of the needle under direct vision. Because of the small numbers involved, no attempt has been made to compare the results for histological diagnosis at laparoscopy with those ottuinined by other methods. A fairly consistent figure of $75-80 \%$ success has been obtained from supragâstric pancreascopy (Kirstaedter and MeyerBurg, 1973), ultrasonic guidance (Hancke et al., 1975) and angiographic placement (Tylén et al., 1976). To determine the relative merits of these techniques, a prospective comparative trial would be required. As no series using more than one method of biopsy has yet been produced, valid data are not available.

A 'minilap' has been advocated in the United States to obtain the same information (Strack et al., 1971). Except where technical difficulties prevent the full procedure, laparoscopy can allow the same sequence of investigations while remaining a lesser procedure that necessitates a much shorter hospital stay; however, unlike a 'minilap', general anaesthesia is required at present.

This series did not consist solely of advanced cases as is shown by the feasibility of resection in 10 of 15 jaundiced patients. Of the lesions in the body and tail none was resectable, but in seven sufficient diagnostic information was obtained to obviate laparotomy.

We have found laparoscopy to be a safe and reliable technique for inspection of the upper abdomen and have had no deaths in over 600 examinations. The cases presented here show that it can be used in the investigation of pancreatic disease with a high diagnostic yield. Assessment of the final place for it in the management of these patients must await the analysis of a larger series. Sufficient evidence is available to indicate that precise information can be obtained as to the appearance and anatomy of the lesion, together with the histological proof of its nature. A preliminary laparoscopy may obviate the need for laparotomy in those grossly inoperable cases where palliation is impossible and allow for a more careful planning of resectional surgery in the less advanced condition.

\section{References}

American Cancer Society Statistics, 1975 (1976). CA. A Cancer Journal for Clinicians, 26, 14-29.

Arnesjö, B., Stormby, N., and Åkerman, M. (1972). Cytodiagnosis of pancreatic lesions by means of fine-needle biopsy during operation. Acta Chirurgica Scandinavica, 138, 363-369.

Christoffersen, P., and Poll, P. (1970). Peroperative pancreas aspiration biopsies. Acta Pathologica et Microbiologica Scandinavica, suppl., 212, 28-32.
Cuschieri, A. (1975). Value of laparoscopy in hepatobiliary disease. Annals of the Royal College of Surgeons of England, 57, 33-38.

Endo, Y., Morii, T., Tamura, H., and Okuda, S. (1974). Cytodiagnosis of pancreatic malignant tumors by aspiration, under direct vision, using a duodenal fiberscope. Gastroenterology, 67, 944-951.

Gelder, F. B., Reese, C. J., Moossa, A. R., Hall, T., and Hunter, R. (1978). Purffication, partial characterization and clinical evaluation of a pancreatic oncofetal antigen. Cancer Research, 38, 313-324.

Haaga, J. R., Alfidi, R. J., Havrilla, T. R., Tubbs, R., Gonzalez, L., Meaney, T. F., and Corsi, M. A. (1977). Definitive role of CT scanning of the pancreas. The second year's experience. Radiology, 124, 723-730.

Hancke, S., Holm, H. H., and Koch, F. (1975). Ultrasonically guided percutaneous fine needle biopsy of the pancreas. Surgery, Gynecology and Obstetrics, 140, 361-364.

Hatfield, A. R. W., Smithies, A., Wilkins, R., and Levi, A.J. (1976). Assessment of endoscopic retrograde cholangiopancreatography (ERCP) and pure pancreatic juice cytology in patients with pancreatic disease. Gut, 17, 1421.

Hermreck, A. S., Thomas, C. Y. IV, and Friesen, S. R. (1974). Importance of pathologic staging in the surgical management of adenocarcinoma of the exocrine pancreas. American Journal of Surgery, 127, 653-657.

Kirstaedter, H. J., and Meyer-Burg, J. (1973). Puntatzytologie des Pankreas und der Pankreastumoren unter Laparoskopischer. Verhandlungen der Deutschen Gessellschraft fur Pathologie, 57, 379-383.

Meyer-Burg, J., Ziegler, U., and Palme, G. (1972). Zur Supragastralen Pankreaskopie. Ergebnisse aus 125 Laparoskopien. Deutsche Medizinische Wochenschrift, 97, 19691971.

Nakase, A., Matsumoto, Y., Uchida, K., and Honjo, I. (1977). Surgical treatment of cancer of the pancreas and periampullary region. Annals of Surgery, 185, 52-57.

Okuda, K., Tanikawa, K., Emura, T., Kuratomi, S., Jinnouchi, S., Urabe, K., Sumikoshi, T., Kanda, Y., Fukuyama, Y., Musha, H., Mori, H., Shimokawa, Y., Yakushiji, F., and Matsuura, Y. (1974). Nonsurgical, percutaneous transhepatic cholangiography-diagnostic significance in medical problems of the liver. American Journal of Digestive Diseases, 19, 21-36.

Osnes, M., Serck-Hanssen, A., and Myren, J. (1975). Endoscopic retrograde brush cytology (ERBC) of the biliary and pancreatic ducts. Scandinavian Journal of Gastroenterology, 10, 829-831.

The Registrar General's Statistical Review of England and Wales for the Three Years 1968-1970, Supplement on Cancer. (1975). HMSO: London.

Sauer, R., Fahrländer, H., and Fridrich, R. (1973). Comparison of the accuracy of liver scans and peritoneoscopy in benign and malignant primary and metastatic tumours of the liver. 222 confirmed cases examined by both methods simultaneously. Scandinavian Journal of Gastroenterology, 8, 389-394.

Sheedy, P. F. II, Stephens, D. H., Hattery, R. R., and MacCarty, R. L. (1977). Computed tomography in the evaluation of patients with suspected carcinoma of the pancreas. Radiology, 124, 731-737.

Shorey, B. A. (1975). Aspiration biopsy of carcinoma of the pancreas. Gut, 16, 645-647.

Smith, E. H., Bartrum, R. J. Jr, Chang, Y. C., D'Orsi, C. J., Lokich, J., Abbruzzese, A., and Dantono, J. (1975). Percutaneous aspiration biopsy of the pancreas under ultrasonic guidance. New England Journal of Medicine, 292, 825-828.

Smith, R. (1961). Pancreatic neoplasms. Proceedings of the 
Royal Society of Medicine, 54, 1124-1126.

Smith, R. (1973). Progress in the surgical treatment of pancreatic disease. American Journal of Surgery, 125, 143153.

Strack, P. R., Newman, H. K., Lerner, A. G., Green, S. H., Meng, C. H., Del Guercio, L. R. M., and State, D. (1971). An integrated procedure for the rapid diagnosis of biliary obstruction, portal hypertension and liver disease of uncertain etiology. New England Journal of Medicine, 285, 1225-1231.
Tylén, U., Arnesjö, B., Lindberg, L. G., Lunderquist, A., and Åkerman, M. (1976). Percutaneous biopsy of carcinoma of the pancreas guided by angiography. Surgery, Gynecology and Obstetrics, 142, 737-739.

Wilson, S. M., and Block, G. E. (1974). Periampullary carcinoma. Archives of Surgery, 108, 539-544.

Wood, R. A. B., Moossa, A. R., Blackstone, M. O., Bowie, J., Collins, P., and Lu, C. T. (1976). Comparative value of four methods of investigating the pancreas. Surgery, 80, 518522.

\section{The June 1978 Issue (Festschrift for Professor Dame Sheila Sherlock)}

\section{THE JUNE 1978 ISSUE CONTAINS THE FOLLOWING PAPERS}

List of contributors

Professor Dame Sheila Sherlock JoHN McMICHAEL

A Fellow at the Free RICHARD SMALLwood

Aguecheek's disease w. H.J. SUMMERSKILL (Reprint)

Alpha-1-antitrypsin deficiency: a biological enigma A. G. BEARN

New insights into the classification and mechanisms of hereditary, chronic, non-haemolytic hyperbilirubinaemias P. BERTHELOT AND D. DHUMEAUX

Twenty-five years of progress in bilirubin metabolism (1952-77) BARBARA H. BILLING

Serum bile acids in hepatobiliary disease IAN A. D. BOUCHIER AND C. R. PENNINGTON

Reabsorption of sodium in the proximal renal tubule in cirrhosis of the liver L. CHIANDUSSI, E. BARTOLI, AND $\mathbf{S}$. ARRAS

\section{Regulation of blood ammonia A. M. DAWSON}

Long-term follow-up of chronic active hepatitis of moderate severity J. DE GROOTE, J. FEVERY, AND L. LEPOUTRE

Congenital hepatic fibrosis: the long-term prognosis D. N. S. KERR, STELLA OKONKWO, AND R. G. CHOA

Recognition of alcoholic liver disease in a district general hospital A. J. LEVI AND D. M. CHALMERS

Plasma lipids and lipoproteins in liver disease NEIL MCINTYRE
The liver in hereditary haemorrhagic teleangiectasia: an inborn error of vascular structure with multiple manifestations: a reappraisal G. A. MARTINI

Relationship between serum ferritin and total body iron stores in idiopathic haemochromatosis $\mathbf{L}$. W. POWELL, J. W. HALLIDAY, AND J. L. COWLISHAW

Some clinical features of liver cell failure: an appraisal of their causes A. E. READ

Advantages of treatment of ascites without sodium restriction and without complete removal of excess fluid T. B. REYNOLDS, F. L. LIEBERMAN, AND A. R. GOODMAN

Liver biopsy in chronic hepatitis: 1968-78 P. J. SCHEUER

Epithelial cell proliferation in diverse models of experimental cholelithiasis A. J. SCOTT

Intracellular electrolyte depletion in patients with ileostomies L. A. TURNBERG A. I. MORRIS, P. C. HAWKER, K. J. HERMAN, R. A. SHIELDS, AND C. E. HORTH

Clinical and pathological study of asymptomatic HBsAg carriers in Chile MARTA VELASCO, $M$. GONZÁlEZ-CERON, CARMEN DE LA FUENTE, AMALIA RUIZ, S. DONOSO, AND R. KATZ

Hepatosplenic schistosomiasis: a great neglected disease of the liver $\mathrm{K}$. S. WARREN

Trials and tribulations with artificial liver support ROGER WILLIAMS

Notes and activities; Books

Copies are still available and may be obtained from the PUBLISHING MANAGER, BRITISH MEDICAL ASSOCIATION, TAVISTOCK SQUARE, LONDON WC1H $9 \mathrm{JR}$, price $£ 2 \cdot 75$, including postage 